\title{
Martín Sánchez-Jankowski: Cracks in the Pavement. Social Change and Resilience in Poor Neighborhoods. University of California Press, 2008, 487 pp., ISBN 978-0-520-25675-0
}

\author{
Gwen van Eijk
}

Received: 13 March 2009/Accepted: 28 July 2009/Published online: 4 September 2009

(C) The Author(s) 2009. This article is published with open access at Springerlink.com

This book takes up an important question: are poor neighbourhoods socially disorganized? As the author describes in the Introduction, the idea that poor neighbourhoods are disorganized has become "conventional wisdom" in many current studies. Disorganization, in the tradition of the Chicago School, denotes the "breakdown" of communities as they are unable to achieve mutual interests and exercise social control to eliminate social problems. Whereas in the past scholars such as Whyte, Gans, Suttles and Lewis have refuted this perspective, recently scholars such as W. J. Wilson and Massey and Denton have reintroduced the notion of social disorganization. This book convincingly challenges this now prevailing paradigm. Through describing processes of change and preservation, the role of agents from both inside and outside neighbourhoods, and the "subculture of scarcity", the book aims to show how poor neighbourhoods are indeed organized.

The book is based on 9 years of ethnographic research in five neighbourhoods-two in Los Angeles and three in New York City. All neighbourhoods house newly arrived migrants and over fifty per cent of the residents live at or below the official poverty level. Within these areas, five establishments in the neighbourhoods are studied: public housing projects, mom-and-pop stores, hair shops, gangs and high schools. The author spent considerable time hanging around and socializing in these establishments and was able to blend in and listen in on conversations between people who were going about their usual business. This provides the reader with in-depth information that might have not become available through formal interviews, where the relationship between researcher and subjects will always impose on the conversation.

The first chapter outlines the theoretical and conceptual framework of the study, which is further developed and illustrated in the following ten chapters that, in pairs, describe the five establishments. The first chapter of each pair provides a description of the establishment's role in the neighbourhoods; the second chapter describes processes of social change and preservation. There is not enough space here to describe all chapters so I will

G. van Eijk ( $\square)$

OTB Research Institute for Housing Urban and Mobility Studies, Delft University of Technology,

P.O Box 5030, 2600 GA Delft, The Netherlands

e-mail: g.vaneijk@tudelft.nl 
focus on the key ideas and provide a few examples that will give an impression of how the empirical data supports the main argument.

The central idea of the book is that social change and preservation happens through the five establishments, but depending on the type of institution and type of neighbourhood, the institutions have different roles in the process of change. Establishments can be "state institutions" or "commercial enterprises", governed by dominant norms of the state or by market principles, or they can be "neighbourhood institutions". In the latter case, establishments embody and reinforce the local subculture-in this way they organize social interaction and behaviour. Establishments can develop from neighbourhood institutions into state or commercial institutions, or the other way around. For example, mom-and-pop stores (Chaps. 4, 5) become neighbourhood institutions when they supply provisions that residents demand, such as ethnic-specific products and financial services. Socializing at the stores also facilitates job networks through which residents learn about job opportunities and what to say during job interviews. The other way around, when owners focus on increasing profits only this has an impact on social networks because people are no longer allowed to just socialize, or the physical space for interaction is limited. When people frequent other stores the enterprise-store loses its role in organizing interaction and behaviour.

Further, the role of establishments and change agents will vary according to whether a neighbourhood is "contested" or "fragmented". In both the residents are socially divided, but in the first they are divided along ethnic boundaries, while in the latter the division is between social substrata-based on value orientations, length of residence, employment and job status, gender, and so on. In fragmented neighbourhoods stores integrate substrata, whereas in contested neighbourhoods stores serve a specific ethnic group only, thereby maintaining the divisions. Neighbourhoods can change from being contested to fragmented and vice versa, due to the influx of new groups or residential stability. For instance, when a new ethnic group starts frequenting a particular store and drives other clients to other shops, the role of the store changes along with, and reinforces the new ethnic divisions in the neighbourhood.

Another example of the role of neighbourhood establishments in change and preservation is how preservation agents such as students, parent groups, gangs and teachers seek to turn high schools-inherently state-oriented-into neighbourhood institutions (Chaps. 10, 11). Here Sánchez-Jankowski stresses that it is important to distinguish rejection of the dominant culture from acts of embracing the local subculture. Students are not so much deliberately counteracting the learning system but are engaged in issues that link to their daily lives-talking not about exams and grades but about conflicts between local gangs and crazy behaviour of peers. The school's role in neighbourhood change becomes apparent when the building of new affordable housing influences the composition of the high school's student body and in turn changes the curriculum, or when fires change the ethnic balance in the neighbourhood which sometimes leads to conflicts at the schools, in turn reinforcing ethnic conflicts between residential groups.

Overall the book offers a detailed and thoughtful account of the role of neighbourhood establishments which is invaluable for understanding neighbourhood change and stability. The author's argument that "there is no way to understand the longevity of poor neighbourhoods through disorganization theory" (p. 8) could perhaps have been taken a step further. The question remains whether it makes sense to talk about neighbourhoods as organized or disorganized entities. Sánchez-Jankowski accepts that neighbourhoods can experience "social death". But is it the neighbourhood that is organized? Or is it rather that neighbourhood institutions provide its residents with structures that help them organize 
their daily lives and shape their orientations and relationships? It may be especially these in-depth analyses - the kind that this book offers - that are needed to develop social policies that are most promising in changing the lives of people living in poverty for the better: a shift of focus away from aggregated levels of crime, unemployment or school drop-outs and towards the daily lives of the people that live in these areas.

Open Access This article is distributed under the terms of the Creative Commons Attribution Noncommercial License which permits any noncommercial use, distribution, and reproduction in any medium, provided the original author(s) and source are credited. 